\title{
Práticas geoconservacionistas como ferramentas para o ensino de Geografia Física
}

\author{
Geoconservationalists practices as tools for physical geography teaching \\ BAPTISTA ${ }^{1}$, E. M. C.; LIMA², I. M. M. F.; SILVA ${ }^{3}$, B. R. V. \\ baptistaeli@gmail.com
}

\begin{abstract}
Resumo
Este trabalho tem como objetivo identificar e analisar práticas conservacionistas que possam ser aplicadas ao ensino de Geografia Física, em face da aproximação desta com o estudo da geodiversidade. A Geoconservação tem por finalidade valorizar e conservar a geodiversidade, definida como os elementos abióticos, interações e sistemas decorrentes das paisagens, dentre as quais se encontram os aspectos estudados pela Geografia Física. No sentido de se conservar a natureza, preocupação social recorrente, os processos educativos se apresentam como mola propulsora desta tarefa. Para desenvolvimento do trabalho foi empregada a pesquisa bibliográfica a partir de Chizotti (2011), Oliveira (2013) e Prodanov e Freitas (2013). A compatibilização entre Geoconservação e o ensino de Geografia Física estabelece-se principalmente a partir da análise da paisagem e de seus componentes fisiográficos, através de diversas práticas geoconservacionistas dentre elas aulas de campo, visitas orientadas a museus, oficinas, cursos e minicursos e trilhas interpretativas. Ainda tem-se muito que avançar neste campo, pois as pesquisas reconhecem o valor educativo da geodiversidade, em sua maioria indicando-a como recurso para a compreensão da dinâmica do ambiente natural, e construir um conhecimento sobre os componentes abióticos das paisagens necessitando, assim, ampliar os estudos nesta perspectiva, principalmente no ensino da Geografia Física.
\end{abstract}

Palavras-chave: Geoconservação; processos educativos; ensino de geografia física.

\begin{abstract}
This work aims to identify and analyze conservation practices that can be applied to Physical Geography teaching, considering its approximation with the study of geodiversity. Geoconservation goals to value and conserve geodiversity, defined as the abiotic elements, interactions and systems resulting from landscapes, among which are the aspects studied by Physical Geography. In the sense of preserving nature, a recurrent social concern, educational processes are the driving force behind this task. For the development of the work the bibliographic research was used from Chizotti (2011), Oliveira (2013) and Prodanov and Freitas (2013). The compatibility between Geoconservation and the teaching of Physical Geography is mainly based on the analysis of the landscape and its physiographic components, through several geoconservationists practices, among them field lessons, guided visits to museums, workshops, courses and mini-courses and interpretive trails. There is still much to be done in this field, since research recognizes the educational value of geodiversity, mostly indicating it as a resource for understanding the dynamics of the natural environment, and building knowledge about the abiotic components of landscapes, needing to expand studies in this perspective, especially in the teaching of Physical Geography.
\end{abstract}

Keywords: Geoconservation; educational processes; physical geography teaching.

\section{INTRODUÇÃO}

A intensificação dos problemas socioculturais, econômicos e ambientais que vem sendo enfrentados pela sociedade tem indicado como solução a Educação, na perspectiva de

${ }^{1}$ Elisabeth Mary de Carvalho Baptista, Núcleo de Estudos sobre a Zona Costeira do Estado do Piauí, Universidade Estadual do Piauí, Teresina-PI, Brasil.

${ }^{2}$ Iracilde Maria de Moura Fé Lima, Departamento de Geografia e História, Universidade Federal do Piauí, Teresina-PI, Brasil

${ }^{3}$ Brenda Rafaele Viana da Silva, Grupo Geomorfologia, Análise Ambiental e Educação, Universidade Federal do Piauí, Teresina-PI, Brasil.. 
que os processos educativos possam contribuir para a formação de uma consciência ambiental no que diz respeito às relações dos seres humanos com a natureza, com eles mesmos e com seus semelhantes. No entanto, é preciso questionar se esta afimativa pode ser generalizada para todas as situações.

Neste sentido, Gonçalves e Diehl (2012, p. 29) consideram que "a base das ações educativas deve visar a formação de cidadãos éticos e participativos que estabeleçam uma relação respeitosa e harmoniosa consigo mesmo, com os outros e com o ambiente". Entendese, assim, que a harmonia pretendida entre sociedade e natureza permeia pelo menos três possibilidades: a necessidade de se conhecer a composição e estrutura do meio ambiente, como este funciona em sua dinâmica natural considerando suas interrelações e, principalmente, se a aquisição deste conhecimento com a finalidade de contribuir com a conservação ambiental proporciona reflexoes sobre a maneira como cada individuo utiliza os recursos naturais.

No campo do conhecimento científico a Geografia, principalmente diante da importância ou relevância adquirida pela relação sociedade-natureza, se configura enquanto uma ciência voltada para a compreensão dos fenômenos ou fatos desenvolvidos pelas sociedades nos ambientes que as cercam e suas consequências. No entanto, as preocupações com a ação antrópica sobre o meio e a resposta desse meio a essa ação é motivo para questionamentos no sentido de harmonizar essa convivência. Assim como estão vinculados homem-natureza ou sociedade-natureza, no que concerne a configuração no tempo e no espaço, esse vínculo deveria ser mantido também no que se refere às pesquisas e ao ensino da Geografia, notadamente em relação à Geografia Física, que incorpora em seu escopo a análise dos aspectos físico-naturais do ambiente, abrangendo os geomorfológicos, climatológicos, pedológicos, hidrográficos e biogeográficos.

Estes aspectos constituem-se, assim, componentes da geodiversidade, definida segundo Kozlowski (2004, p. 834), como "a variedade natural da superfície da Terra, referindo-se a aspectos geológicos e geomorfológicos, solos e águas superficiais, bem como a outros sistemas criados como resultado de processos naturais (endogênicos e exógenos) e da atividade humana" percebendo-se a relação com a análise empreendida pela Geografia Física. $\mathrm{Na}$ perspectiva crescente do interesse pela conservação da natureza e de seus recursos, a geodiversidade prescinde de reconhecimento e valorização de seus componentes pela sociedade e para que isto aconteça processos educativos contínuos e significativos serão necessários. 
Este contexto possibilitou o desenvolvimento da Geoconservação, processo ou ciência emergente conforme preconizam Henriques et al (2011) que tem por finalidade valorizar e conservar a geodiversidade, seus elementos, interações e sistemas inseridos na paisagens, nas quais se encontram os aspectos estudados pela Geografia Física. No escopo da Geoconservação, buscando compatibilizar as ações para conservação da geodiversidade, encenam-se exemplos de práticas educativas com o propósito de conhecer, sensibilizar e divulgar a diversidade natural das diferentes paisagens.

Deste modo, constitui objetivo deste trabalho identificar e analisar práticas geoconservacionistas que possam ser empregadas para facilitar o ensino-aprendizagem dos aspectos naturais da paisagem com aplicação em diferentes níveis de ensino da Geografia Física.

\section{METODOLOGIA}

Para este trabalho foi empregada a pesquisa bibliográfica, dada a natureza da pesquisa que pretendeu investigar na literatura especializada as possibilidades para o ensino da Geografia Física através da Geoconservação, considerando as perspectivas de Chizzotti (2011), Oliveira (2013) e Prodanov e Freitas (2013), estudiosos deste procedimento metodológico. Livros (impressos e e-books), artigos publicados em periódicos, teses de doutorado, dissertações de mestrado e trabalhos publicados em Anais de eventos científicos, se constituíram nas fontes para este estudo e a feitura do presente texto.

O desenvolvimento do trabalho perpassou pela seguinte sequência metodológica: a) levantamento dos autores e textos teóricos para subsidiar a fundamentação conceitual da pesquisa; b) elaboração do texto referente à fundamentação teórica visando apresentar sucintamente aspectos do contexto educacional em suas modalidades; c) identificação de diferentes práticas da Geoconservação que possam ser aplicadas ao ensino de Geografia Física; d) reflexões acerca das possibilidades de emprego destas práticas.

\section{RESULTADOS E DISCUSSÃO}

Não se configura um processo simples e de fácil desenvolvimento discutir-se a dimensão educacional na Geoconservação considerando a geodiversidade dos lugares, que implica em diferentes formas de buscar sua proteção, mas também na diversidade cultural, histórica e social de cada sociedade envolvida na questão. 
Tratar de Educação primeiramente remete-se a explicitar de forma resumida as três modalidades do processo educativo, conhecidos como formal, não formal e informal. Essa tipologia do contexto educacional é explicada por Bruno (2014, p. 12) ao afirmar que:

O entendimento da educação como um processo amplo e abrangente e a importância de se equacionarem diferentes modalidades educativas presentes nas práticas sociais, como forma de contornar a hegemonia da forma escolar, permitiu a emergência de uma tipologia de modalidades educativas referidas como educação formal, não formal e informal (BRUNO, 2014, p. 12).

Assim, a educação formal organiza-se por se desenvolver em um ambiente determinado em nível oficial para este fim, a não formal encontra-se em espaços denominados não escolares, mas do qual se escolhe participar e a informal é aquela relacionada a um contexto de socialização. Gohn (2006, p. 29) ao referir-se a estes espaços explica que:

\footnotetext{
Na educação formal estes espaços são os do território das escolas, são instituições regulamentadas por lei, certificadoras, organizadas segundo diretrizes nacionais. $\mathrm{Na}$ educação não-formal, os espaços educativos localizam-se em territórios que acompanham as trajetórias de vida dos grupos e indivíduos, fora das escolas, em locais informais, locais onde há processos interativos intencionais (a questão da intencionalidade é um elemento importante de diferenciação). Já a educação informal tem seus espaços educativos demarcados por referências de nacionalidade, localidade, idade, sexo, religião, etnia etc. A casa onde se mora, a rua, o bairro, o condomínio, o clube que se freqüenta, a igreja ou o local de culto a que se vincula sua crença religiosa, o local onde se nasceu, etc. (Sic).
}

Pode-se inferir que as possibilidades para os processos educativos são significativas no sentido do contexto espacial. Entretanto é possível entender também que se diferenciam no que concerne ao conteúdo, ao que se ensina. Neste caso, as diferenciações dos campos do conhecimento também vão induzir a uma diversificação nas formas de se ensinar.

No caso da Geografia Física tem-se apostado muito nos trabalhos realizados em campo no sentido de uma melhor compreensão dos processos naturais que organizam o espaço geográfico ou o meio ambiente. Neste aspecto Conti (2011, p. 520) diferencia aula de campo de trabalho de campo (grifo nosso), ao dizer que a primeira se constitui em um "recurso do qual se lança mão quando as experiências de aprendizagem não podem ser realizadas dentro da sala de aula ou em um laboratório", que quando bem realizada estimula a interação entre a escola e o meio, produzindo bons resultados. Portanto, o trabalho de campo para ele, volta-se mais para a pesquisa em si e a aula é uma estratégia didática direcionada ao ensino.

Também a utilização de maquetes, diferentes tipos de jogos, textos literários (como romances, poemas, crônicas), recursos da geotecnologia, por meio do geoprocessamento, além obviamente dos tradicionais mapas, fazem parte da realidade do ensino da Geografia 
Física, com proporções e intensidades que variam, principalmente de acordo com o nível de ensino, formação do professor, perfil socioeconômico cultural dos alunos e estrutura do espaço educacional (seja qual for a modalidade).

Para esta compreensão muitos métodos perpassam o caminho dos estudiosos da Geografia Física como, dentre outros, a análise da paisagem a partir da concepção sistêmica. Nunes et al $(2006$, p. 8; 14) refletindo sobre a questão do método na análise da Geografia Física especialmente do quadro ambiental expressam que:

O que se espera é que a Geografia, em especial a Geografia Física, construa uma visão plena dos processos de produção da natureza, onde natureza e sociedade sejam integradas, independente da verticalização do tema, ou do recorte espacial, a serem adotados nos estudos geográficos. [...]

Assim, é primordial que a Geografia Física detentora desta perspectiva possa agregar outros conhecimentos e em conjunto com outras ciências, em um nítido processo interdisciplinar, seja capaz de colaborar com a construção de conceitos e análises sobre o mundo em que se vive em todos os espaços educacionais possíveis. As diferentes categorias de análise da Geografia, ou conceitos-chaves, abraçam esta perspectiva, pois mesmo a partir dos elementos geomorfológicos, climatológicos, pedológicos, hidrográficos etc., é pertinente uma relação intrínseca com a ação/atuação dos seres humanos. Importa recordar que sobre o espaço geográfico as atividades humanas se produzem e reproduzem, em intensidades que acabam por desconfigurar por completo a fisionomia original da paisagem construindo outro espaço, mesmo ainda que, predominantemente antrópico, geográfico.

\subsection{Geoconservação e Geografia Física}

A Geoconservação vem se desenvolvendo significativamente a partir da última década do século XX e primeira do século XXI com o propósito de proteger e conservar o ambiente terrestre a partir de seus elementos abióticos, ou seja sua geodiversidade, conforme preconizam autores como Nieto (2001), Sharples (2002), Gray (2005, 2011), Brilha (2005, 2016), Paulo Pereira (2006), Ricardo Pereira (2010), entre outros, quando se trata de estudos em âmbito internacional. No Brasil, estes estudos derivam de temporalidade mais recente a partir da segunda metade da década de 2000, tendo já muitos pesquisadores envolvidos nesta temática, entre os quais se pode citar Ruchkys (2007), Nascimento, Ruchkys e Mantesso-Neto (2008), Mansur (2010) e muitos outros. Embora gerada a partir dos estudos da Geologia, a Geoconservação ganha cada vez mais adeptos dentre os geógrafos e professores de Geografia, 
notadamente aqueles que se definem no estudo dos aspectos físicos da paisagem e suas interrelações.

É notória e estreita a relação que a Geografia Física possui com a Geoconservação, a se considerar o conceito de geodiversidade que, de acordo com Gray (2005, p. 5), corresponde a "variação natural (diversidade) de aspectos geológicos (rochas, minerais, fósseis), geomorfológicos (formas da Terra, processos físicos) e de solo. Inclui suas composições, relações, propriedades, interpretações e sistemas", sendo esta a prioridade das ações geoconservacionistas. Destarte, a partir deste conceito identifica-se a Geografia Física como relevante colaboradora para a compreensão da geodiversidade terrestre, compondo junto com a Geologia e outros campos do conhecimento também correlatos às denominadas Geociências ou Ciências da Terra.

Cabe destacar que dentre as subáreas da Geografia Física a geomorfologia tem sido aquela que mais delineia pesquisas e estudos relacionados à geodiversidade e Geoconservação, em face de definição de geomorfossítios e indicação destes como patrimônio geomorfológico. Ressalta-se, ainda, a importância do geoturismo, enquanto estratégia geoconservacionista, que leva em consideração a contemplação, valorização e estudo dos aspectos da geodiversidade, inseridos na Geografia Física.

Pode-se acrescentar, a partir de Lavor (2016, p. 32), que "nos estudos voltados para a ocupação e uso de uma dada porção do espaço geográfico, o conhecimento da geodiversidade é essencial diante das diversas questões ambientais que surgem no decorrer do processo de ocupação humana". Isto implica necessariamente no estudo desta geodiversidade para estabelecer critérios para planejamento dos espaços geográficos, considerando, é claro, a interação com a sociedade.

Além disso, a paisagem constitui-se, dentre as categorias de análise da Geografia a que mais se aproxima da Geoconservação, por se relacionar diretamente com a geodiversidade, sendo assim adequada para a compreensão das questões relacionadas à dinâmica do meio ambiente e à conservação da natureza.

Neste sentido, Meira e Morais (2016) argumentam que para se realizar estudos sobre o patrimônio geológico e concretizar ações de geoconservação é fundamental o planejamento territorial-ambiental o qual, historicamente está fortemente relacionado à Geografia, se constituindo em conjunto com a gestão o ápice dos estudos geográficos. Estudos esses que interpretam os aspectos físicos da paisagem em conjunto com as atividades sociais presentes, e por isto os autores consideram que a "categoria de análise geográfica "Paisagem" pode ser amplamente empregada nos estudos da geodiversidade" (MEIRA; MORAIS, 2016, p. 140). 
Dantas et al (2015, p. 11) afirmam que "a análise integrada da paisagem constitui um dos instrumentos metodológicos mais relevantes para os estudos de geodiversidade", considerando ainda que "a paisagem natural ou a paisagem geomorfológica é uma fração da paisagem geográfica e, portanto, o objeto de estudo, por excelência, dos estudos de Geodiversidade" (grifo dos autores).

Por isso, entende-se que o conceito de paisagem, notadamente na perspectiva natural, muito discutido nos estudos geográficos, configura-se na principal interface entre Geografia Física e Geoconservação.

\subsection{Ensino de Geografia Física e Geoconservação}

No que concerne ao ensino de Geografia Física considera-se que esta deve proporcionar a leitura da paisagem natural de forma que o aluno possa observar, descrever, comparar e analisar fenômenos presentes, desenvolvendo habilidades cognitivas, hierarquicamente mais complexas. Neste aspecto, Saraiva Junior (2013) entende que as concepções de embasamento das metodologias do Ensino de Geografia relacionam-se aos conceitos de natureza e ambiente e de paisagem como categoria de análise do espaço geográfico.

Silva e Rodriguez (2014) refletem que em função das complexas inter-relações entre sociedade e natureza e as alterações nos ciclos biogeoquímicos e socioeconômicos, se define uma diversificação nas feições dos espaços que demandam, para sua análise, diagnóstico e gestão, abordagens novas a partir de uma perspectiva inter e transdisciplinar, pautada no respeito aos diferentes conhecimentos e procedimentos teórico-metodológicos, possibilitando integrar a outras ciências, os conhecimentos geográficos. No contexto educacional enfatizam que:

[...] nas práticas da didática geográfica, é necessário conjugar os diferentes eixos temáticos e curriculares da Ciência Geográfica, de forma a se poder efetivar uma síntese da leitura da realidade socioambiental dos territórios bem como co-relacionar seus problemas e potencialidades de forma a propiciar as bases necessárias a um planejamento e gestão corrente e participante. O papel didático da Geografia é essencial para que todo cidadão possa conhecer a realidade de seus lugares e assim direcionar esforços para uma autodeterminação e gestão comunitária eficiente (SILVA; RODRIGUEZ, 2014, p. 7).

Também é preciso levar em conta a complexidade dos conteúdos da Geografia Física, expressa em suas características integradas na compreensão do funcionamento da dinâmica natural sobre o espaço geográfico. Se entender essa complexidade demanda esforço de estudos sistemáticos e aprofundados, imagine ensinar esses conteúdos de forma acessível ao 
entendimento dos alunos em sua diversidade cognitiva. Destarte, Silva e Silva (2017, p. 3) afirmam que:

O ensino da Geografia Física representa um grande desafio para os professores da educação básica, pois a mesma é composta por uma ampla e diversificada quantidade de termos técnicos, que são utilizadas para nomear, diferenciar e identificar os fenômenos naturais e os mais variados tipos de morfologias encontradas no nosso espaço geográfico.

Na metodologia do ensino da Geografia Física significativos estudos tratam de apontar diferentes e diversificadas possibilidades didático-pedagógicas que podem ser aplicadas nas diferentes âmbitos da Educação. Neste panorama identifica-se uma diversidade e quantidade significativa de metodologias, técnicas, ferramentas e recursos para se ensinar os aspectos fisiográficos da Geografia a partir da leitura de vários autores. Importa esclarecer que não há uniformidade no emprego dos termos, alguns se confundindo, não sendo a distinção destes, no entanto, propósito deste trabalho, mas tornando-se necessário definir que aqui será empregado o termo técnica para quando se tratar dos procedimentos e recursos quando se indicar materiais concretos utilizados.

A tabela 01 sintetiza estas técnicas e recursos, a partir das sugestões de diversos estudiosos, acompanhadas de uma breve descrição e finalidade educacional.

Tabela 01. Sugestões metodológicas para o ensino de Geografia Física. Fonte: Org. das Autoras (2018).

\begin{tabular}{|c|c|c|c|c|}
\hline \multicolumn{5}{|c|}{ Sugestões metodológicas para o ensino de Geografia Física } \\
\hline Técnicas & Descrição & Finalidade & Recursos & Autores \\
\hline Reálias & $\begin{array}{l}\text { Adoção de objetos } \\
\text { para representar um } \\
\text { assunto, situação ou } \\
\text { simular uma } \\
\text { realidade, podendo } \\
\text { ser reais modelos } \\
\text { e/ou miniaturas. }\end{array}$ & \begin{tabular}{|c|} 
Auxiliar na \\
proposição de \\
situações-problemas \\
ou análise de casos e \\
fortalecer o \\
entendimento de \\
significados de \\
palavras ou conceitos \\
de realidades abstratas \\
ou distantes dos \\
alunos.
\end{tabular} & $\begin{array}{l}\text { Rochas, fósseis, } \\
\text { frações de solo, } \\
\text { maquetes, etc. }\end{array}$ & $\begin{array}{c}\text { Louzada e } \\
\text { Frota Filho, } \\
2017 .\end{array}$ \\
\hline Terrário & $\begin{array}{l}\text { Utilização de } \\
\text { qualquer objeto } \\
\text { quase idêntico à } \\
\text { estrutura da } \\
\text { paisagem original } \\
\text { ou reprodução } \\
\text { integral de um } \\
\text { ecossistema em } \\
\text { miniatura, dentro de } \\
\text { um recipiente. }\end{array}$ & $\begin{array}{l}\text { Auxiliar na exposição } \\
\text { de determinados } \\
\text { conteúdos com } \\
\text { objetos inanimados, } \\
\text { como por exemplo, } \\
\text { apresentar os tipos de } \\
\text { biomas (composição), } \\
\text { regime hidrológico, } \\
\text { tipos de solo, tipos de } \\
\text { vegetação, etc. }\end{array}$ & $\begin{array}{c}\text { Garrafas PET, } \\
\text { aquários, lâmpadas, } \\
\text { copos entre outros } \\
\text { objetos. }\end{array}$ & $\begin{array}{c}\text { Louzada e } \\
\text { Frota Filho, } \\
2017 .\end{array}$ \\
\hline
\end{tabular}




\begin{tabular}{|c|c|c|c|c|}
\hline $\begin{array}{c}\text { Aula de Campo } \\
\text { / Trabalho de } \\
\text { Campo }\end{array}$ & $\begin{array}{c}\text { Atividade de } \\
\text { incursão á realidade } \\
\text { a partir de } \\
\text { planejamento } \\
\text { prévio, com } \\
\text { supervisão do } \\
\text { professor. }\end{array}$ & $\begin{array}{l}\text { Relacionar a teoria } \\
\text { com a práxis, através } \\
\text { de inserções a campo. }\end{array}$ & \begin{tabular}{|c|} 
Variados de acordo \\
com o objetivo da \\
pesquisa, em geral \\
caderneta de campo, \\
equipamentos de \\
localização (GPS, \\
bússola) e de \\
registro visual \\
(máquina \\
fotográfica). \\
\end{tabular} & $\begin{array}{c}\text { Silva e } \\
\text { Rodrigues, } \\
2014 ; \\
\text { Louzada e } \\
\text { Frota Filho, } \\
2017 .\end{array}$ \\
\hline Estudo do Meio & $\begin{array}{l}\text { Inserções em campo } \\
\text { para visualizar } \\
\text { fenômenos sociais e } \\
\text { naturais orientados } \\
\text { pelo professor, com } \\
\text { base nas temáticas } \\
\text { trabalhadas. }\end{array}$ & $\begin{array}{c}\text { Auxiliar na } \\
\text { compreensão dos } \\
\text { conhecimentos } \\
\text { cotidianos ou } \\
\text { empíricos, } \\
\text { relacionados com os } \\
\text { temas estudados em } \\
\text { sala de aula, através } \\
\text { de investigação. } \\
\end{array}$ & $\begin{array}{l}\text { Variados de acordo } \\
\text { com a finalidade da } \\
\text { atividade }\end{array}$ & $\begin{array}{c}\text { Louzada e } \\
\text { Frota Filho, } \\
2017 .\end{array}$ \\
\hline Mapas Mentais & $\begin{array}{l}\text { Representação do } \\
\text { espaço, através da } \\
\text { percepção dos } \\
\text { próprios alunos. }\end{array}$ & $\begin{array}{l}\text { Elaborar desenhos } \\
\text { para representar no } \\
\text { papel aspectos } \\
\text { observados no } \\
\text { entorno, em relação } \\
\text { ao cotidiano, ou } \\
\text { aspectos físicos e } \\
\text { naturais, em uma } \\
\text { prática de campo. }\end{array}$ & $\begin{array}{c}\text { Material para } \\
\text { desenho livre (papel, } \\
\text { lápis, borracha, } \\
\text { coleção de cor, etc.). }\end{array}$ & $\begin{array}{c}\text { Louzada e } \\
\text { Frota Filho, } \\
2017 .\end{array}$ \\
\hline $\begin{array}{l}\text { Trilha de } \\
\text { Orientação }\end{array}$ & \begin{tabular}{|c|} 
Modalidade \\
desportiva que \\
possibilita leitura, \\
interpretação e \\
produção de mapas, \\
permitindo melhor \\
compreensão do \\
espaço geográfico. \\
\end{tabular} & $\begin{array}{l}\text { Utilizar a prática } \\
\text { cotidiana de } \\
\text { percepção do espaço, } \\
\text { acrescida do aspecto } \\
\text { lúdico de uma } \\
\text { atividade desportiva. }\end{array}$ & $\begin{array}{l}\text { Mapas, imagens e } \\
\text { outros produtos } \\
\text { cartográficos. }\end{array}$ & $\begin{array}{c}\text { Silva e } \\
\text { Rodrigues, } \\
\text { 2014; } \\
\text { Sabota e } \\
\text { Bueno, } \\
\text { 2013/2014. }\end{array}$ \\
\hline $\begin{array}{c}\text { Perfil } \\
\text { geoecológico }\end{array}$ & $\begin{array}{c}\text { Representação } \\
\text { vertical da } \\
\text { paisagem, com } \\
\text { distinção das feições } \\
\text { paisagísticas a ela } \\
\text { intrínseca. }\end{array}$ & $\begin{array}{l}\text { Facilitar a correlação } \\
\text { da leitura dos } \\
\text { elementos naturais da } \\
\text { paisagem e o } \\
\text { entendimento de sua } \\
\text { representação. }\end{array}$ & $\begin{array}{c}\text { Ferramentas de } \\
\text { Geoprocessamento e } \\
\text { de edição } \\
\text { (hardwares e } \\
\text { softwares) }\end{array}$ & $\begin{array}{c}\text { Almeida, } \\
\text { Ribeiro e } \\
\text { Vidal, } 2017 .\end{array}$ \\
\hline $\begin{array}{l}\text { Tecnologias de } \\
\text { Informação e } \\
\text { Comunicação }\end{array}$ & $\begin{array}{c}\text { Ferramentas de } \\
\text { informação e } \\
\text { comunicação que } \\
\text { somados aos estudos } \\
\text { proporciona } \\
\text { liberdade } \\
\text { responsável no seu } \\
\text { uso viabilizando o } \\
\text { processo } \\
\text { educacional, como } \\
\text { por exemplo, através } \\
\text { de audiovisual. }\end{array}$ & $\begin{array}{l}\text { Contribuir com o } \\
\text { processo de ensino- } \\
\text { aprendizagem } \\
\text { facilitando o } \\
\text { entendimento dos } \\
\text { conceitos e } \\
\text { proporcionando a } \\
\text { inserção na sociedade } \\
\text { tecnológica. }\end{array}$ & $\begin{array}{l}\text { TV multimídia, } \\
\text { Vídeos diversos, } \\
\text { Computador, } \\
\text { Internet }\end{array}$ & $\begin{array}{l}\text { Torres, 2011; } \\
\text { Silva e } \\
\text { Rodrigues, } \\
2014 ; \\
\text { Periçato et al } \\
2015 .\end{array}$ \\
\hline
\end{tabular}




\begin{tabular}{|c|c|c|c|c|}
\hline Jogos & $\begin{array}{c}\text { Situações de } \\
\text { aprendizagem que } \\
\text { propiciam a } \\
\text { interação entre } \\
\text { alunos e professores }\end{array}$ & \begin{tabular}{|c|} 
Articular diferentes \\
informações \\
geográficas; facilitar a \\
habilidade de \\
formular conceitos; \\
desenvolver a \\
capacidade de análise; \\
criar situações para o \\
entendimento do \\
conteúdo geográfico; \\
contribuir para a \\
construção do \\
raciocínio e de \\
relações de \\
sociabilidade entre os \\
alunos. \\
\end{tabular} & $\begin{array}{c}\text { Tabuleiro, Cartas, } \\
\text { Bingo, Dominó, } \\
\text { entre outros. }\end{array}$ & $\begin{array}{c}\text { Sousa, } \\
\text { Barbosa e } \\
\text { Andrade, } \\
2015 .\end{array}$ \\
\hline Maquetes & $\begin{array}{c}\text { Representação } \\
\text { tridimensional da } \\
\text { geomorfologia, } \\
\text { permitindo a } \\
\text { visualização das } \\
\text { formas topográficas. }\end{array}$ & $\begin{array}{l}\text { Possibilitar melhor } \\
\text { compreensão dos } \\
\text { conteúdos. }\end{array}$ & $\begin{array}{l}\text { Argila, isopor; } \\
\text { galhos secos, tinta } \\
\text { guache, gel de } \\
\text { cabelo, garrafas pet, } \\
\text { e outros, } \\
\text { dependendo do } \\
\text { objeto a ser } \\
\text { representado. }\end{array}$ & $\begin{array}{c}\text { Silva e Silva, } \\
2017 .\end{array}$ \\
\hline
\end{tabular}

Certamente não se esgotam aqui as possibilidades para o ensino de Geografia Física, mas a partir destas infere-se que tanto o professor como os alunos possuem a seu dispor uma gama de técnicas e ferramentas de ensino, que podem ser aplicadas em qualquer nível e modalidade educativa, respeitadas as especificidades de cada grupo envolvido. Também é importante comentar que não se exclui o emprego do livro didático, mas se intenciona somar a este, outras formas de facilitar a aprendizagem, principalmente no contexto da Geografia Física.

Mas, e a Geoconservação? Como suas ações ou práticas podem contribuir para o ensino da Geografia Física? Como já enfatizado, a proximidade dos conhecimentos priorizados neste processo é intrínseco ao conhecimento da Geografia Física, articulando-se os aspectos geomorfológicos, pedológicos, hidrológicos e climatológicos da paisagem. Entretanto, existem práticas específicas da Geoconservação atestada por aqueles que a investigam e a desenvolvem em distintos espaços e em diferentes países, visando proteger o patrimônio natural do planeta.

Quando se trata de estratégias de Geoconservação considera-se as etapas para sua concretização que de acordo com Brilha (2005) consistem em: Inventariação, Quantificação, Classificação, Conservação, Valorização e Divulgação e Monitoração, tendo estas sido objeto de diferentes roteiros de aplicação dependendo do objetivo da pesquisa e das características da 
área de estudo, como por exemplo o proposto por Meira et al (2017) desenvolvido através de quatro procedimentos distintos em seis etapas sendo assim resumido pelos autores:

\begin{abstract}
i) Pré-inventário: composto pelas etapas de definição da área de estudo e pelo detalhamento do meio físico; ii) Inventário dos geossítios: compreende a inventariação dos locais de interesse geológico geomorfológico; iii) Avaliação dos Geossítios: composta pela avaliação qualitativa e/ou quantitativa dos geossítios inventariados; e, iv) Valorização e divulgação dos geossítios: contempla as etapas de seleção dos geossítios a serem valorizados/divulgados e o planejamento de ações de conservação.
\end{abstract}

Observa-se que no processo de execução de uma estratégia de Geoconservação, podese empregar diferentes técnicas e que certamente se adéquam para aplicação no ensino da Geografia Física, haja visto sua relação com este processo como já exposto. Além disso, o valor educativo da geodiversidade implica em se trabalhar em todos os âmbitos e níveis de ensino visando o seu conhecimento, valorização, divulgação e conservação, nos diferentes saberes das Geociências, como a Geografia Física. Também as ações a serem planejadas para a conservação da geodiversidade ou do patrimônio natural, geológico e geomorfológico de qualquer espaço geográfico perpassam seguramente pela Educação.

Relaciona-se na tabela 02 práticas geoconservacionistas específicas, algumas comumente já empregadas no ensino de Geografia Física, como o trabalho de campo, que podem ser incorporadas as já citadas na tabela 01 .

Da mesma forma, não se pretende esgotar a indicação dessas práticas, pois a cada dia novas possibilidades surgem a partir das investigações sobre geodiversidade e Geoconservação que se ampliam no panorama da pesquisa brasileira. As práticas são apresentadas a partir de suas atividades, modalidade de ensino para a qual pode ser aplicada e objetivos propostos, e podem ser adaptadas pelos professores ou responsáveis por seu desenvolvimento, levando em consideração logicamente o perfil do público envolvido no processo educativo (alunos, comunidade etc.), bem como as condições de infraestrutura dos espaços formais ou logística dos não formais e informais.

Tabela 02. Práticas Geoconservacionistas para o Ensino de Geografia Física. Fonte: Org. das Autoras (2018).

\title{
Práticas Geoconservacionistas para o Ensino de Geografia Física
}

\begin{tabular}{c|c|l}
\hline Atividade & Ensino & \multicolumn{1}{|c}{ Objetivos } \\
\hline $\begin{array}{c}\text { Aula de Campo / } \\
\text { Trabalho de Campo }\end{array}$ & Formal / Não formal & $\begin{array}{l}\text { Aproximar o aluno da área de estudo visando à } \\
\text { compreensão da realidade. }\end{array}$ \\
\hline Geoturismo & $\begin{array}{c}\text { Não formal / } \\
\text { Informal }\end{array}$ & $\begin{array}{l}\text { Desenvolver visitas orientadas em espaços de com } \\
\text { relevantes atributos da geodiversidade para o } \\
\text { conhecimento e valorização dos aspectos fisiográficos } \\
\text { da paisagem. }\end{array}$ \\
\hline
\end{tabular}




\begin{tabular}{|c|c|c|}
\hline Visita a Museus & Não formal & $\begin{array}{l}\text { Conhecer e reconhecer paleoambientes e o passado } \\
\text { geológico da Terra. }\end{array}$ \\
\hline $\begin{array}{l}\text { Experimentos em } \\
\text { Laboratório }\end{array}$ & Formal & $\begin{array}{l}\text { Manusear elementos concretos da geodiversidade } \\
\text { visando entender suas características e suas relações } \\
\text { com outros aspectos da paisagem, como solos, } \\
\text { hidrografia, etc. }\end{array}$ \\
\hline $\begin{array}{l}\text { Produção de material } \\
\text { didático / informativo }\end{array}$ & Formal & $\begin{array}{l}\text { Elaborar produtos que possam facilitar a compreensão } \\
\text { sobre a dinâmica terrestre, principalmente no que se } \\
\text { refere a aspectos da Geografia Física. }\end{array}$ \\
\hline Oficinas & $\begin{array}{c}\text { Formal / Não formal } \\
\text { / Informal }\end{array}$ & $\begin{array}{l}\text { Integrar teoria e prática e possibilitar a construção do } \\
\text { conhecimento por meio de ações. Corresponde ao } \\
\text { aprender fazendo. }\end{array}$ \\
\hline Cursos e Minicursos & $\begin{array}{c}\text { Formal / Não formal } \\
\text { / Informal }\end{array}$ & $\begin{array}{l}\text { Expor e discutir sobre os aspectos físicos da paisagem } \\
\text { visando à ampliação do conhecimento e reforço da } \\
\text { aprendizagem dos conteúdos geográficos. }\end{array}$ \\
\hline Trilhas interpretativas & $\begin{array}{l}\text { Não formal / } \\
\text { Informal }\end{array}$ & $\begin{array}{l}\text { Atividade de contato com a natureza através de } \\
\text { caminhadas que possibilita a interpretação e } \\
\text { conhecimento das feições geológicas dos percursos, } \\
\text { principalmente quando guiadas. }\end{array}$ \\
\hline
\end{tabular}

Essas práticas podem ser descritas da seguinte forma a partir das possibilidades que apresentam no contexto do ensino da Geografia Física:

- Aulas de campo para conhecimento in loco de estruturas geológicas, feições geomorfológicas, tipos pedológicos e elementos hidrográficos, além de buscar entender os processos integrados destes componentes da paisagem.

- Geoturismo, atividade de "visita organizada e orientada a locais que testemunham uma fase do passado ou da história de origem e evolução do planeta, que se notabilizam como uma herança coletiva e que devem ser preservados para as gerações futuras" (MOURA FÉ et al, 2016, p. 831), possibilitando o conhecimento de diferentes áreas que possuem características geodiversas relevantes ou em áreas protegidas, Unidades de Conservação ou Geoparques.

- Visita a Museus para estudo e conhecimento de paleoambientes e paleogeografia, no intuito de se entender o passado do planeta e reconhecer a importância das ciências relacionadas a estes conhecimentos como a Paleontologia, a Geologia e outros.

- Aulas ou atividades em laboratórios envolvendo experimentos com rochas, associadas ao relevo e tipos de solo.

- Produção de material didático/informativo sobre espaços geográficos em estudo e suas características geográficas.

- Desenvolvimento de oficinas, minicursos e cursos estendidos para aperfeiçoamento teórico e prático dos conhecimentos geográficos no âmbito da Geografia Física. 
- Trilhas interpretativas, que colaboram para o conhecimento e valorização de aspectos geológicos e geomorfológicos em percursos definidos e preferencialmente guiados por profissionais.

Reforça-se então que muitas destas práticas já se configuram concernente às análises em Geografia Física, o que aproxima ainda mais a Geoconservação com o estudo geográfico dos aspectos da paisagem. Bacci (2018, p. 108), tratando de estratégias educativas voltadas para a Geoconservação lembra que estas "pautam-se fundamentalmente em processos educativos voltados aos conhecimentos do Sistema Terra, ou seja, rochas, minerais, solos, paisagens, processos geológicos, e outros que preservam a história do planeta, ao longo de milhões e bilhões de anos". Conhecimentos estes que se encontram relacionados diretamente com a leitura da Geografia Física.

Deste modo, é evidente que predominam entre as práticas geoconservacionistas elencadas atividades fora do ambiente escolar, fora dos "muros da escola" e da sala de aula, aquelas que se denominam Aula de Campo ou Trabalho de Campo, o geoturismo, visitas a Museus e as trilhas interpretativas.

Segundo Machado e Ruchkys (2010, p. 54-55) “o museu é um espaço de produção e divulgação de conhecimento, portanto locus de contato entre a ciência e a sociedade" e deste modo tem muito a contribuir com o conhecimento da história do passado da Terra e dos homens que nela habitavam. As autoras ainda afirmam que "[...] é premente a necessidade de desenvolvimento de projetos educativos ligados à geoconservação reconhecendo as ligações entre geologia, solos, habitats, paisagens e processos naturais". Assim, para o contexto da Geografia Física a partir da Geoconservação visitar estes espaços deve proporcionar interesse na compreensão sobre a evolução geológica, mas também geomorfológica, climática, hidrográfica e biogeográfica do planeta bem como as transformações de suas paisagens no decorrer da passagem do tempo.

Com respeito às oficinas, Paviani e Fontana (2009) reconhecem que estas possibilitam no contexto do ensino vivenciar situações concretas e significativas a partir da possibilidade da relação entre a percepção, o pensamento e a ação, sendo assim uma estratégia de integração entre teoria e prática. Deste modo o conhecimento se constrói através do agir, mas a partir de uma base teórica relacionada ao tema em discussão. Pezente et al (2012, p. 773), por sua vez, indicam que a realização de oficinas estimula "a participação e o espírito de colaboração dos envolvidos tornando mais eficiente a aprendizagem, pois esta ocorre de maneira natural e espontânea, resultando numa melhor compreensão das questões abordadas", 
permitindo desenvolver a colaboração, estimular a criatividade e fomentar habilidades para produção de materiais didáticos.

Os minicursos e cursos, geralmente de cunho mais teórico, têm como finalidade apresentar/discutir de forma sucinta e objetiva ou de maneira mais detalhada e extensa sobre os aspectos relacionados à Geografia Física, respectivamente, incluindo neste contexto a geodiversidade. Vale acrescentar que as oficinas, minicursos e cursos podem ser desenvolvidos em todas as modalidades educacionais.

Já os experimentos laboratoriais e produção de material educativo/informativo, geralmente necessitam de um espaço formal no que se refere ao processo didático pedagógico. No entanto, a respeito do laboratório, Liccardo e colaboradores vêm desenvolvendo desde 2011, "a aplicação de uma prática de externalização do conteúdo e "abertura" do laboratório, de maneira que o acesso às amostras pudesse ser otimizado e disponibilizado ao máximo" aos alunos da Educação Básica em espaços de passagem dentro da Universidade Estadual de Ponta Grossa (UEPG), no Paraná (LICCARDO; PIMENTEL; PRANDEL, 2013, p. 128).

Interessante destacar que no caso do emprego do geoturismo com fins didáticos, Bento e Araújo (2014, p. 135) entendem que este "[...] contribui também para o enriquecimento das aulas de geografia, pois, dinamiza o aprendizado proporcionado a entre a teoria e a prática do trabalho de campo". Assim, conjuga-se mais de uma prática na atividade geoturística, por possibilitar conhecimento, contemplação e valorização da geodiversidade e, claro, dos conteúdos da Geografia Física.

As trilhas interpretativas também se inserem como atividade geoturística e podem, além de contribuir para o conhecimento da geodiversidade, como estratégia de Geoconservação, reduzir riscos geológicos, uma vez que podem minimizar possíveis danos ao solo, por exemplo, a partir de sua delimitação. Isto porque o pisoteio e a compactação decorrente, ficarão restritos a uma área menor, sendo possível o seu controle através da elaboração de plano de manejo (GUIMARÃES; MARIANO, 2015).

Nesta perspectiva do contexto educacional Paz e Frick (2015, p. 5) asseveram que é possível compreender a relação entre os conceitos sobre geodiversidade e Geoconservação e o cotidiano dos alunos, ao se trabalhar com eles, permitindo "[...] a formação de cidadãos mais conscientes e críticos e consequentemente consumidores mais responsáveis, o que irá contribuir para uma gestão/uso mais sustentável dos recursos naturais (bióticos e abióticos)".

Portanto, a Geoconservação pode sim contribuir para o ensino dos conteúdos de Geografia Física, sendo suas práticas e ferramentas relevantes tanto para a consolidação 
teórico-conceitual como para aproximações com o espaço geográfico real, visando integrar conhecimento e respeito para a conservação da natureza.

\section{CONSIDERAÇÕES FINAIS}

A indicação de ferramentas para se desenvolver o ensino em qualquer campo científico se traduz em uma tarefa que requer conhecimento, disposição e planejamento. $\mathrm{Na}$ Educação, seja qual for sua modalidade: formal, não formal e informal, estudar aspectos da Geografia da Terra, em suas características físicas, é essencial para se compreender as fragilidades e fortalezas dos elementos que compõem suas distintas paisagens, sua dinâmica e inter-relações, visando a partir deste conhecimento estabelecer vínculos de respeito para com a natureza ressoando em ações concretas de conservação ambiental.

Assim, a Geoconservação através de práticas que visam conhecer, valorizar, divulgar e proteger a geodiversidade, também pode contribuir para o desenvolvimento do ensino da Geografia Física de forma mais eficiente e por que não dizer, prazerosa. Na mesma perspectiva, a Geografia Física também pode contribuir para os estudos e desenvolvimento da Geoconservação através da interpretação e análise dos processos que atuam e modelam as paisagens, e deste modo o conhecimento sobre aspectos da paisagem através do ensino ou processos educativos, pode levar ao estabelecimento da valorização e conservação destes.

Por fim, destaca-se que o trabalho de campo corresponde a prática geoconservacionista que mais se coaduna com o ensino da Geografia Física, pelo seu caráter prático de aproximação da realidade do espaço geográfico, mas todas as práticas relacionadas podem e devem também possibilitar uma aprendizagem mais consistente do conhecimento geográfico em questão.

Mesmo não tendo esgotado o assunto, não se teve esta pretensão, espera-se ter colaborado com uma reflexão sobre os laços que cada vez mais se estreitam no que se refere à Geoconservação e à Geografia Física, sem, no entanto perder de vista a importância da relação entre a sociedade e a natureza, interlocutores dos processos que se desenvolvem sobre a superfície terrestre.

\section{REFERÊNCIAS}

ALMEIDA, E. P.; RIBEIRO, M. C. A.; VIDAL, M. R. V.. Elaboração de materiais didático no ensino de geografia física na Reserva indígena Kyikateje a partir da construção de perfis 
geoecológico. In SIMPÓSIO DE PRODUÇÃO CIENTIFICA, 1., 2017, Marabá, PA. Anais [...]. Marabá, PA: UNIFESSPA, 2017. v. 1, p. 1-3.

BACCI, D. L. C. Estratégias educativas para a Geoconservação. In SANTOS, V. M. N.; JACOBI, P. R. (org.). Educação, Ambiente e Aprendizagem Social: Reflexões e Possibilidades a Geoconservação e Sustentabilidade. Curitiba CRV, 2018. 246 p.

BENTO, L. C. M.; ARAÚJO, M. S. Geoturismo e Geoconservação: Uma prática de campo. In SIMPÓSIO MINEIRO DE GEOGRAFIA, 1., 2014, Alfenas, MG. Anais [...]. Alfenas, MG: UFA, 2014. p. 132-145.

BRILHA, J. B. R. Inventory and Quantitative Assessment of Geosites and Geodiversity Sites: A Review. Geoheritage, v. 8. Switzerland: 2016.

BRILHA, J. B. R. Patrimônio geológico e geoconservação: a conservação da natureza na sua vertente geológica. Braga: Palimage, 2005. 190 p.

BRUNO, A. Educação formal, não formal e informal: da trilogia aos cruzamentos, dos hibridismos a outros contributos. Mediações, v. 2, n. 2. Setúbal, Portugal: 2014.

CHIZZOTTI, A. Pesquisa qualitativa em ciências humanas e sociais. 4. ed. Petrópolis: Vozes, 2011. 144 p.

CONTI, J. B. Contos de Campo. In VENTURI, L. A. B. (org.). Geografia: Práticas de Campo, Laboratório e Sala de Aula. São Paulo: Sarandi, 2011. 528 p.

DANTAS, M. E.; ARMESTO, R. C. G.; SILVA, C. R., SHINZATO, E. Geodiversidade e análise da paisagem: uma abordagem teórico-metodológica. Terræ Didatica, v.11, n. 1. Campinas: 2015.

GUIMARÃES, T. O.; MARIANO, G. Uso de Trilhas como Estratégia de Geoconservação. Anuário do Instituto de Geociências - UFRJ, v. 38, n. 1. Rio de Janeiro: 2015.

GOHN, M. G. Educação não formal, participação da sociedade civil e estruturas colegiadas nas escolas. Ensaio, v.14, n.50. Rio de Janeiro: 2006.

GONÇALVES, C. S.; DIEHL, L. S. Integrando sala de aula e ambiente. In LISBOA, C. P.; KINDEL, E. A. I. (org.). Educação Ambiental: da teoria à prática. Porto Alegre: Mediação, 2012. $142 \mathrm{p}$.

GRAY, M. Geodiversity and Geoconservation: What, Why, and How? The George Wright Forum, v. 22, n. 3. Hancock, USA: 2005.

GRAY, M. Other nature: geodiversity and geosystem services. Environmental Conservation, v. 38, n. 3. Cambridge, UK: 2011.

HENRIQUES, M. H.; REIS, R. P.; BRILHA, J. B. R.; MOTA, T. Geoconservation as an Emerging Geoscience. Geoheritage, n. 3. Switzerland: 2011. 
KOZLOWSKI, S. Geodiversity. The concept and scope of geodiversity. Przeglad Geologiczny, v. 52, n. 8/2. Warszawa, Poland: 2004.

LAVOR, L. F. Geodiversidade e sítios históricos na porção terminal do baixo curso do rio Paraíba do Norte. Dissertação de Mestrado em Geografia apresentada ao Programa de Pós-Graduação em Geografia da Universidade Federal da Paraíba, 2016. 174 p.

LICCARDO, A.; PIMENTEL, C. S.; PRANDEL, J. A. Estratégia de educação não formal de geociências pela externalização do conteúdo do laboratório didático de Geologia. In ENCUENTRO DE GEOGRAFOS DE AMERICA LATINA, 14., 2013, Lima, Peru. Anales [...]. Lima, Peru: Unión Geografica Internacional, 2013. v. 1. p. 125-134.

LOUZADA, C. O.; FROTA FILHO, A. B. Metodologias para o ensino de Geografia Física. Geosaberes, v. 8, n. 14. Fortaleza: 2017.

MACHADO, M. M. M.; RUCHKYS, Ú. A. Valorizar e divulgar a geodiversidade: Estratégias do Centro de Referência em Patrimônio Geológico CRPG - MHNJB/UFMG.

Geonomos, v. 18, n. 2. Belo Horizonte: 2010.

MANSUR, K. L. Diretrizes para Geoconservação do Patrimônio Geológico do Estado do Rio de Janeiro: o caso do Domínio Tectônico Cabo Frio. Tese de Doutorado em Ciências Geologia apresentada ao Programa de Pós-Graduação em Geologia do Instituto de Geociências da Universidade Federal do Rio de Janeiro, 2010. 214 p.

MEIRA, S. A.; MORAIS, J. O. Os conceitos de geodiversidade, patrimônio geológico e geoconservação: abordagens sobre o papel da geografia no estudo da temática. Boletim de Geografia, v. 34, n. 3. Maringá: 2016.

MEIRA, S. A.; NASCIMENTO, M. A. L.; SÁ, A. A. A.; SILVA, E. V. O Caminho das Pedras - Uma Proposta de Roteiro Metodológico para Atividades Práticas em Geoconservação. Estudos Geográficos, v. 15, n. 2. Rio Claro: 2017.

MOURA FÉ, M. M.; PINHEIRO, M. V. A.; JACÓ, D. M.; OLIVEIRA, B. A. Geoeducação: A Educação Ambiental aplicada na Geoconservação. In SEABRA, G. (org.). Educação Ambiental \& Biogeografia. Ituiutaba: Barlavento, 2016. 2762 p

NASCIMENTO, M. A. L.; RUCHKYS, Ú. A.; MANTESSO-NETO, V. Geodiversidade, Geoconservação e Geoturismo: trinômio importante para a proteção do patrimônio geológico. São Paulo: Sociedade Brasileira de Geologia, 2008. 84 p.

NIETO, L. M. Geodiversidad: propuesta de una definición integradora. Boletín Geológico y Minero, v. 112, n. 2. Madrid, España: 2001.

NUNES, J. O. R.; SANT'ANNA NETO, J. L.; TOMMASELLI, J. T. G.; AMORIM, M. C. C. T.; PERUSI, M. C. A influência dos métodos científicos na geografia física. Terra Livre, v. 2, n. 27. São Paulo: 2006.

PAVIANI, N. M. S.; FONTANA, N. M. Oficinas pedagógicas: relato de uma experiência. Conjectura, v. 14, n. 2. Caxias do Sul: 2009. 
PAZ, O. L. S.; FRICK, E. C. L. Geodiversidade e Geoconservação: Possibilidades no âmbito da Educação Ambiental dentro e fora de sala de aula. In ENCONTRO NACIONAL DE ENSINO DE GEOGRAFIA, 7., Catalão/GO. Anais [...]. Catalão/GO: UFG, 2015. p. 1-6.

PEREIRA, P. J. S. Património geomorfológico: conceptualização, avaliação e divulgação. Aplicação ao Parque Natural de Montesinho. Tese de Doutorado em Ciências - Geologia apresentada a Universidade do Minho, Portugal, 2006. 370 p.

PEREIRA, R. G. F. A. Geoconservação e desenvolvimento sustentável na Chapada Diamantina (Bahia-Brasil). Tese de Doutorado em Ciências - Geologia apresentada a Universidade do Minho, Portugal, 2010. 318 p.

PERIÇATO, A. J.; PAES, C. E. R.; SANCHES, C. C.; MANSANO, C. N. O uso de recursos didáticos no ensino da geografia física. ANAP Brasil, v. 8, n. 10. Tupã: 2015.

PEZENTE, M. T.; TOPANOTTI, Z. P.; JESUS, A. C.; GIASSI, M. G. O processo de ensinoaprendizagem através de oficinas pedagógicas. Revista Técnico Científica (IFSC), v. 3, n. 1. Criciúma: 2012.

PRODANOV, C. C.; FREITAS, E. C. Metodologia do trabalho científico: métodos e técnicas da pesquisa e do trabalho acadêmico. 2. ed. Novo Hamburgo: Feevale, 2013. 276 p..

OLIVEIRA, M. M. Como fazer pesquisa qualitativa. 5. ed. Petrópolis: Vozes, 2013. 232 p.

RUCHKYS, Ú. A. Patrimônio geológico e geoconservação no Quadrilátero Ferrífero, Minas Gerais: potencial para a criação de um geoparque da UNESCO. Tese de Doutorado em Geologia apresentada ao Programa de Pós Graduação em Geologia do Instituto de Geociências da Universidade Federal de Minas Gerais, 2007. 211 p.

SABOTA, H. S.; BUENO, M. A. Trilha de orientação: aplicação de uma prática de ensino de Cartografia para a compreensão dos conceitos da geografia física na fase escolar. Territorium Terran, v. 2, n. 3. São João del-Rei: 2013/2014.

SARAIVA JUNIOR, J. C. Tempo Geológico, Sociedade e Ensino de Geografia Física. Holos, ano 29, v. 5. Natal: 2013.

SHARPLES, C. Concepts and principles of geoconservation. Published electronically on the Tasmanian Parks \& Wildlife Service web site. 3. ed. 2002. 81 p. Disponível em: http://dpipwe.tas.gov.au/Documents/geoconservation.pdf. Acesso em: 22/01/2018.

SILVA, E. V.; RODRIGUES, J. M. M. O ensino da Geografia Física: práticas pedagógicas e perspectivas interdisciplinares. Revista Equador, v. 3, n. 2. Teresina: 2014.

SILVA, H. R. C.; SILVA, M. S. F. A construção de maquete como instrumento de ensino e aprendizagem da Geografia Física. In ENCONTRO INTERNACIONAL DE FORMAÇÃO DE PROFESSORES, 10., 2017, Aracaju. Anais [...]. Aracaju: UNIT, 2017. v. 10, p. 1-15.

SOUSA, S. R. C. T.; BARBOSA, A. C.; ANDRADE, C. S. P. Recursos didáticos não convencionais no ensino de geografia: o uso dos jogos lúdicos em sala de aula. In 
ENCUENTRO DE GEÓGRAFOS DE AMÉRICA LATINA, 15., 2015, Havana , Cuba. Anales [...]. Havana, Cuba: Universidad de La Habana, 2015. p. 1426-1432.

TORRES, E. C. Ensino de Geografia Física por meio de audio-visuais. Revista Geográfica de América Central, Edição Especial. San Jose: 2011.

\section{AGRADECIMENTOS}

Expressam-se agradecimentos à Coordenação de Aperfeiçoamento de Pessoal de Nível Superior (CAPES) pela concessão de Bolsa de Pós-doutorado, através do Programa Nacional de Pós-Doutoramento (PNPD/CAPES) para a primeira autora, viabilizando o desenvolvimento das atividades do estágio pós-doutoral, do qual fez parte este trabalho, no Programa de PósGraduação em Geografia da Universidade Federal do Piauí (PPGGEO/UFPI) no período de fevereiro de 2018 a janeiro de 2019.

Agradecem-se ainda ao Grupo de Pesquisa Geomorfologia, Análise Ambiental e Educação (GAAE), da Universidade Federal do Piauí (UFPI) e ao Núcleo de Estudos sobre a Zona Costeira do Estado do Piauí (NEZCPI), da Universidade Estadual do Piauí (UESPI), pelo apoio na investigação realizada.

Recebido em: 11/08/2019

Aceito para publicação em: 01/11/2019 